\title{
Analysis on the Communication Strategy of Chinese Television Drama Bao Zheng and The Untamed in Thailand-Based on Perspective of the " 5 W" Communication Mode
}

\author{
Xianrong Qiao, Wenrui Duan \\ Collage of Arts and Science, Shaanxi University of Science \& Technology, Xi'an, China \\ Email: duanwrkelp@163.com
}

How to cite this paper: Qiao, X.R. and Duan, W.R. (2021) Analysis on the Communication Strategy of Chinese Television Drama Bao Zheng and The Untamed in ThailandBased on Perspective of the " $5 \mathrm{~W}$ " Communication Mode. Open Access Library Journal, 8: e8179.

https://doi.org/10.4236/oalib.1108179

Received: November 11, 2021

Accepted: December 19, 2021

Published: December 22, 2021

Copyright $\odot 2021$ by author(s) and Open Access Library Inc.

This work is licensed under the Creative Commons Attribution International License (CC BY 4.0).

http://creativecommons.org/licenses/by/4.0/

\begin{abstract}
From 1996 to 2019, the Chinese Television Drama Bao Zheng (co-directed by Liang Kaicheng, Sun Shupei, Hou Bowei, Chen Junliang and other 11 people) and The Untamed (directed by Zheng Weiwen and Chen Jialin) are popular in Thailand. The purpose of this paper is improving the influence of Chinese TV dramas overseas. Based on the " $5 \mathrm{~W}$ " Communication Theory and questionnaire survey methods, the author analyzes the reasons for the successful spread of these two television dramas overseas from the spreading process of Bao Zheng and The Untamed, so as to provide the international development countermeasures of Chinese TV series. The result of this paper is that the values promoted by the TV series "Bao Zheng" and The Untamed are consistent with the values of Thailand, and the rapid development of the internet has promoted the overseas dissemination of Chinese TV series. At the same time, content production, overseas dissemination, policy support and translation should be promoted.
\end{abstract}

\section{Subject Areas}

Culture, Journalism and Communication, Linguistics

\section{Keywords}

Chinese Television Drama Overseas Communication, Thailand, TV Series Bao Zheng, TV Series The Untamed

\section{Introduction}

With the continuous advancement of the globalization process and expansion of 
the "Belt and Road" initiative, China's comprehensive national strength and global influence of Chinese culture are gradually increasing throughout the world. As part of the soft power of Chinese culture, Chinese television dramas are being widely spread around the world. Among them, Chinese costume dramas have also conveyed China's unique traditional culture towards the world. Thailand (called "Siam" in ancient times), located in the southwest of China, has had close contacts with China since ancient times. China and Thailand have a history of friendly exchanges for thousands of years. The earliest known spread of ancient Chinese novels in Thailand was in Ming Dynasty [1]. "With the cultural exchange between the two countries, ancient Chinese novels began to spread in Thai society and had a profound influence on it" [2]. Since the Ming Dynasty, due to the deepening of tributary activities, the trade and cultural exchanges between China and Thailand have also been expanding, and there are many Chinese classical books have flowed into Thailand and are loved by the Thai people, such as The Romance of the Three Kingdoms, Journey to the West, and The Investiture of the Gods and so on. During the reign of Thailand's IX King Bhumibol Adulyadej, many Chinese classics were translated into Thai and were widely circulated among the Thai people. One of the famous one is Bao Zheng. In the 1990s, the television drama Bao Zheng co-directed by 11 Chinese directors including Liang Kaicheng, Sun Shupei, Hou Bowei, Chen Junliang, etc. was all the rage in Thailand. Since the day it was broadcast, it has gained high ratings and became the main topic in Thai people's lives. Bao Wenzheng has also become a representative of honest and upright in the hearts of the Thai people.

In different periods, Chinese television dramas have been disseminated overseas in different ways. In the 1990s, the spread of the television drama Bao Zheng mainly relied on the single channel of the TV station for dissemination, and with less offline activities and interactions between actors and fans, but was still a huge success in Thailand relied on high-quality content and values that fit the philosophy of the Thai people. Until 2019, when the television drama The Untamed was launched, the TV station and the internet were simultaneously broadcasted. At the same time, various topics and activities were launched on social platforms such as Facebook and Twitter to attract Thai fans and got great recognition. Bao Zheng and The Untamed have achieved great success in Thailand, but the reasons for the success of these two television dramas are completely different. The author will analyze the reasons for the popularity of television dramas Bao Zheng and The Untamed in Thailand from the perspective of the " $5 \mathrm{~W}$ " dissemination model, and put forward some feasible suggestions for the external dissemination of Chinese television dramas. In order to promote the overseas dissemination of television dramas, we should improve our own content, create high-quality television dramas, broaden overseas communication channels, expand publicity in many ways, and increase the popularity of television dramas overseas, advance policy support, and set up a special translation department to improve translation level. 


\section{Questionnaire Survey on the Spreading Factors of Chinese Television Dramas Bao Zheng and The Untamed in Thailand}

\subsection{Research Methods and Questionnaire Settings}

\subsubsection{Questionnaire Design}

In this research, the author uses a scientific model to analyze the results obtained from the questionnaire. The " $5 \mathrm{~W}$ " communication model, proposed by the founder of American communication studies, Lasswell, analyzes the communication activities of human society and conducts empirical research. It mainly includes the five elements of "Who", "Says What", "In Which Channel", "To Whom", and "With What Effects" [3]. According to the communication subject, the audience, the communication channel, the dissemination content and dissemination effect to set questions, using Google Form online tools to make questionnaires, the author tries to explore the success factors of overseas dissemination of Chinese television dramas in different periods and backgrounds. The author takes the dissemination process of TV series Bao Zheng and The Untamed in Thailand as examples, mainly discusses the channels and significance of Chinese television dramas' overseas dissemination, seeks the overseas dissemination path of television dramas, and provides strategies and suggestions for the overseas dissemination of Chinese culture.

Using Lasswell's " $5 \mathrm{~W}$ " dissemination model for guidance, the author analyzes the factors for the successful dissemination of Chinese television dramas in Thailand on the basis of data. This questionnaire is an anonymous questionnaire. There are 18 questions in total, divided into five parts. The first part analyzes the basic information of the interviewee, including gender, age, occupation, etc., and the second part analyzes the dissemination effect of two television dramas. The analysis includes the degree of awareness of the two television dramas and the reasons for their love. The third part analyzes the interviewees' viewing types of Chinese television dramas, including the types of television dramas they like, the attractiveness of Chinese television dramas, etc. The fourth part analyzes the communication channels, including the channels for obtaining relevant information about television dramas and the length of watching time per week. The fifth part analyzes the interviewees' suggestions on the future development of Chinese television dramas, including the current advantages and disadvantages of Chinese television dramas.

\subsubsection{Sample Selection}

The questionnaire named "Questionnaire on the Dissemination of Chinese Television Dramas Bao Zheng and The Untamed in Thailand" was produced by the author, and the language modification and localization were completed by Thai students. The author sent to 6 Thai friends and their relatives through the internet. At the same time, this questionnaire was also sent to the Thai social media forums and topics related to Chinese television dramas. A total of 65 valid questionnaires filled out by Thai citizens were retrieved in this survey. 


\subsection{Analysis of Survey Results}

The author conducts research and analysis on the questionnaire survey data from the following four perspectives: the audience, the content, the channels, and the effect of the communication. The specific analysis results are as follows:

\subsubsection{Communication Audience Analysis}

Among the 65 valid questionnaires received from the citizens, in the gender distribution, female interviewees accounted for $66.1 \%$, male interviewees accounted for $33.9 \%$, and the gender distribution of interviewees was mostly female; in terms of age distribution, the interviewees between 6 - 18 years old accounted for $23.8 \%$, those aged 19 - 28 accounted for 39.7\%, those aged 29 - 50 accounted for $33.3 \%$, and those over 50 accounted for $3.2 \%$. Most of the interviewees were young and middle-aged. Detailed information will be illustrated in Figure 1.

According to the analysis of the survey results, the majority of interviewees are young and middle-aged Thai women. The distribution channel of this questionnaire consists of two parts, one is the author's Thai friends and their relatives, and the other is distributed on Thai social media platforms related to Chinese television dramas. Most of the questionnaires returned come from social media platforms. According to the analysis of the questionnaire, the majority of the audience who are more interested in Chinese television dramas are women.

\subsubsection{Communication Content Analysis}

The data obtained from the questionnaire survey showed that in the multiple-choice questions of "Types of favorite Chinese TV dramas", 78.5\% of the interviewees chose ancient costume dramas, $50.8 \%$ of the interviewees chose youth dramas, and $36.9 \%$ of the interviewees choose modern dramas. In the multiple-choice question of "Why do they like Chinese TV dramas", 79.7\% of
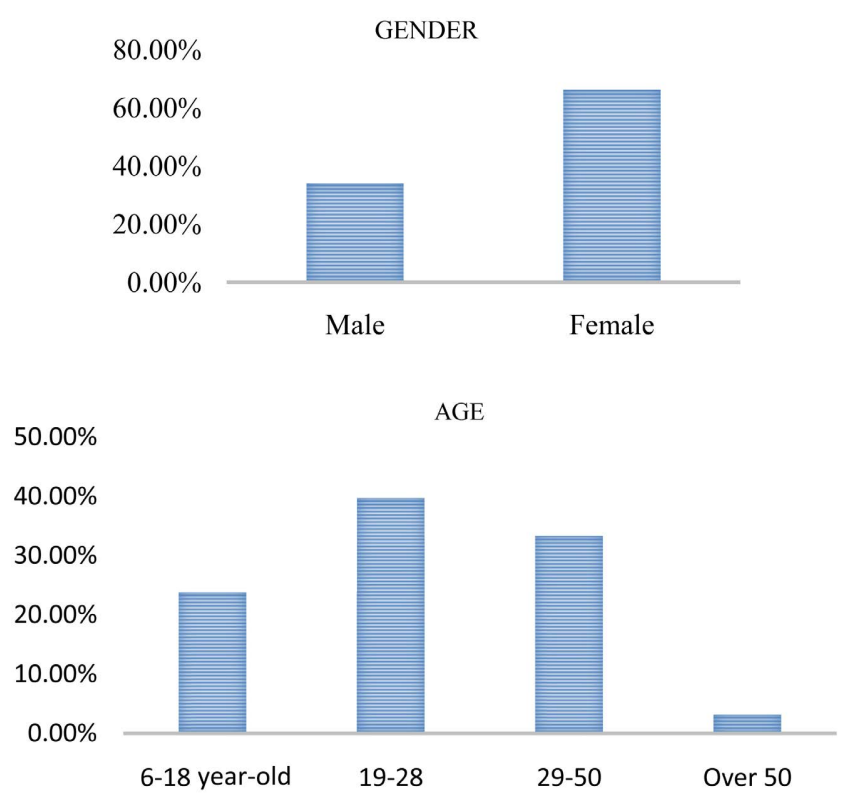

Figure 1. Communication audience analysis. 
the interviewees chose interesting stories, $78.1 \%$ of the interviewees chose Chinese actors, $57.8 \%$ of the interviewees choose to be interested in Chinese culture, $54.7 \%$ of the interviewees choose to learn Chinese through TV dramas, and $51.6 \%$ of the interviewees think TV dramas are well-produced, $46.9 \%$ of the interviewees think they can acquire knowledge, and $32.8 \%$ of interviewees think that the translation is relatively accurate. In the multiple-choice question in the survey "Problems of Chinese TV Dramas", 56.2\% of the interviewees think that Chinese TV dramas are not properly promoted, $23.4 \%$ of the interviewees think that the content of the story is boring, $18.82 \%$ of the interviewees think that some TV shows are the same and have no characteristics, and $17.2 \%$ of the interviewees think that the content of TV shows is too different from Thai culture and far from real life. Detailed information will be illustrated in Figure 2.

According to the analysis of the survey results, the Thai audience's favorite genre of Chinese TV dramas is costume dramas, followed by youth dramas. Chinese costume dramas have unique cultural connotations and artistic expressions. This type of TV drama shows the beauty of traditional Chinese culture, its exquisite traditional costumes, and the unique appeal to audiences at home and abroad. In the survey "Reasons for Love Chinese TV Dramas", most of the interviewees recognized the story content of Chinese TV dramas and liked Chinese actors. More than half of the interviewees believed that Chinese and Chinese culture could be learned through Chinese TV dramas. In the survey "Problems of Chinese TV Dramas", more than half of the interviewees believed that Chinese TV dramas were not properly promoted in Thailand, and nearly a quarter of the interviewees believed that the content of the Chinese TV stories is boring. According to the above analysis, the content of most Chinese TV dramas is very high-quality, and the actors are selected successfully. Chinese culture can be spread while TV dramas are disseminated overseas. However, in the overseas dissemination of TV dramas, the publicity is still insufficient, and the content of some TV dramas is the same.

\subsubsection{Communication Channel Analysis}

The data obtained from the questionnaire survey shows that in the multiple-choice questions on "How did you know about the TV series Bao Zheng, $73.9 \%$ of the interviewees learned about it through TV, and $28.3 \%$ of the interviewees learned about it through social medias, and $15.2 \%$ of the interviewees learned through newspapers and magazines. In the survey of the TV series The Untamed, $85.9 \%$ of the interviewees learned about it through social media, $31.2 \%$ of the interviewees learned about it through TV, and $28.1 \%$ of the interviewees be informed by others. In the multiple-choice question of "Time spent on watching TV series per week", $26.3 \%$ of interviewees watch less than 5 hours a week, $49.2 \%$ watch 5 - 25 hours, and $24.6 \%$ watch 25 more than hours. Detailed information will be illustrated in Figure 3 .

The main channels of dissemination of Chinese TV series in Thailand are social media and mass communication. The main dissemination channel of the TV 
TYPE
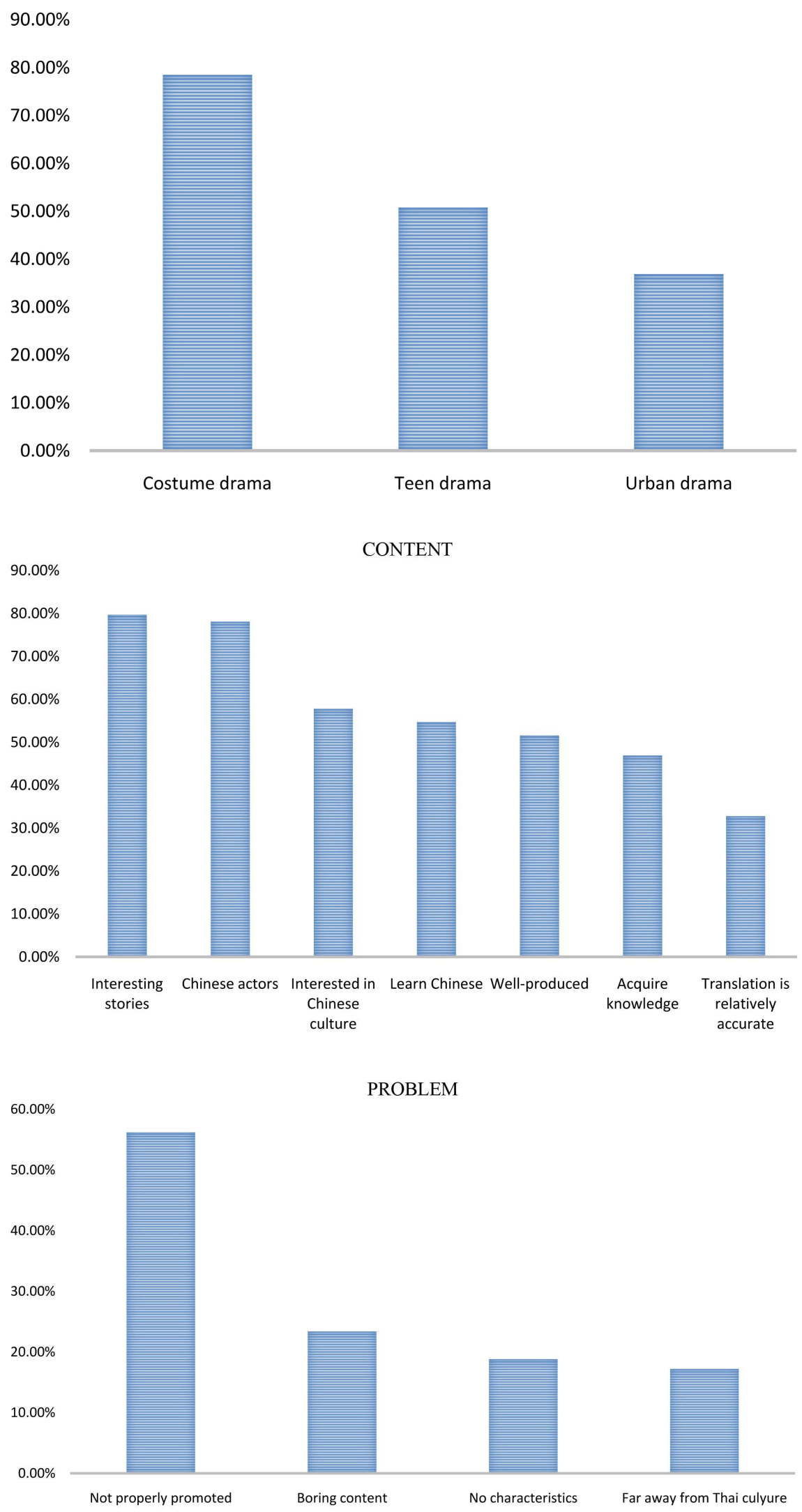

Figure 2. Communication content analysis. 


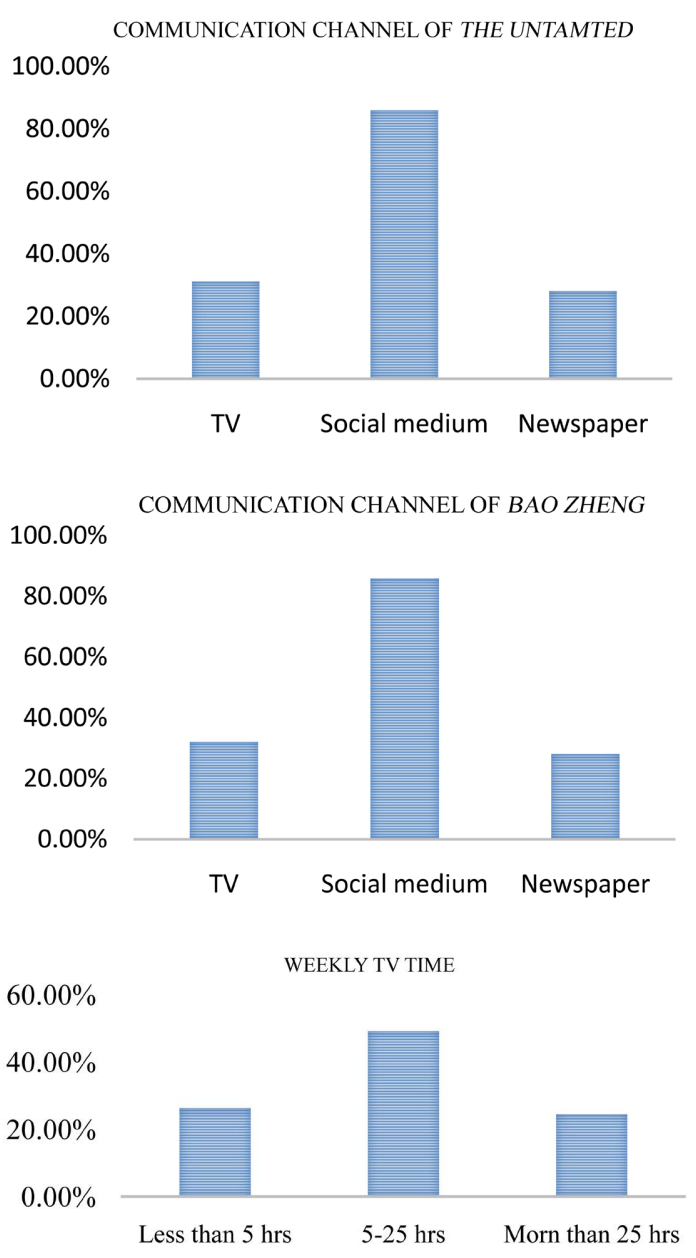

Figure 3. Communication channel analysis.

series Bao Zheng is television, and the main dissemination channel of the TV series The Untamed is social media. Different era backgrounds have determined the channels of dissemination of TV dramas. In the 1990s, the internet in Thailand was not yet popular. The main channel for obtaining information was the mass media. The introduction of TV dramas was mainly determined by the government. Bao Zheng was a great success in this era. In 2019, the internet in Thailand was widely popularized. More than $90 \%$ of Thai citizens use smartphones to access the internet [4]. Thais obtain information through online social media platforms, such as Instagram, Facebook, and Twitter, which makes young people mainly get information about the TV series The Untamed from social media platforms.

\subsubsection{Communication Effect Analysis}

The data obtained from the questionnaire survey showed that the awareness of the TV series Bao Zheng was $96.6 \%, 85.3 \%$ of the interviewees had watched this TV series, and the TV series The Untamed had a recognition rate of $95 \%$ and 83.9\% received the interviewees had watched this TV series. It can be concluded that these two TV series have high recognition in Thailand. In the multiple-choice 
questions in the "Survey on the Reasons for the Love of Two TV Shows", 60\% of the interviewees of the TV series Bao Zheng thought the content of the TV series was interesting and vivid, and $48.4 \%$ of the interviewees said that the series conveyed positive energy and showed in view of the commonality of the cultures of the two countries, $41.5 \%$ of the interviewees believed that the show reflected the social reality at the time, $35 \%$ of the interviewees believed that the actors' acting skills were vivid; the TV series The Untamed, $70.8 \%$ of the interviewees believed that the actors acting skills are vivid, $69.4 \%$ of the interviewees are deeply impressed by the theme song, $64.6 \%$ of the interviewees think that the content of the show is lively and interesting, $56.7 \%$ of the interviewees are attracted by the actors' looks, and $54.8 \%$ of the interviewees think it can pass the part TV series understand Chinese culture. Detailed information will be illustrated in Figure 4 .

\section{REASON FOR THE LOVE OF BAO ZHENG}

$70.00 \%$

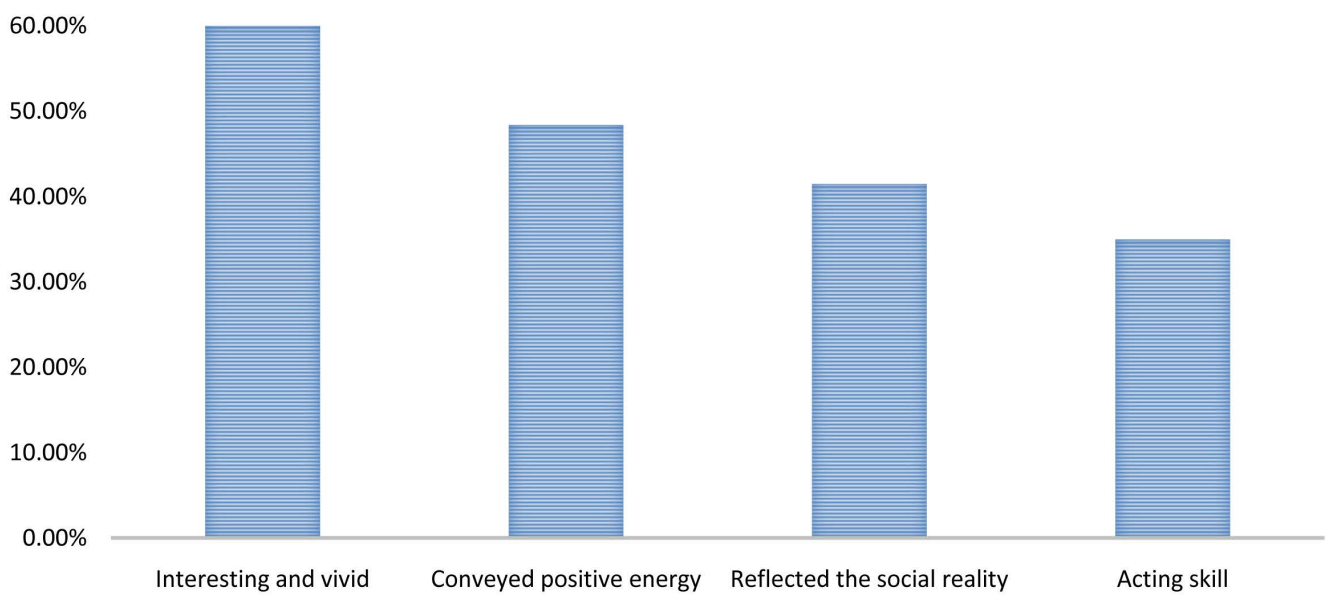

REASON FOR THE LOVE OF THE UNTAMED

$80.00 \%$

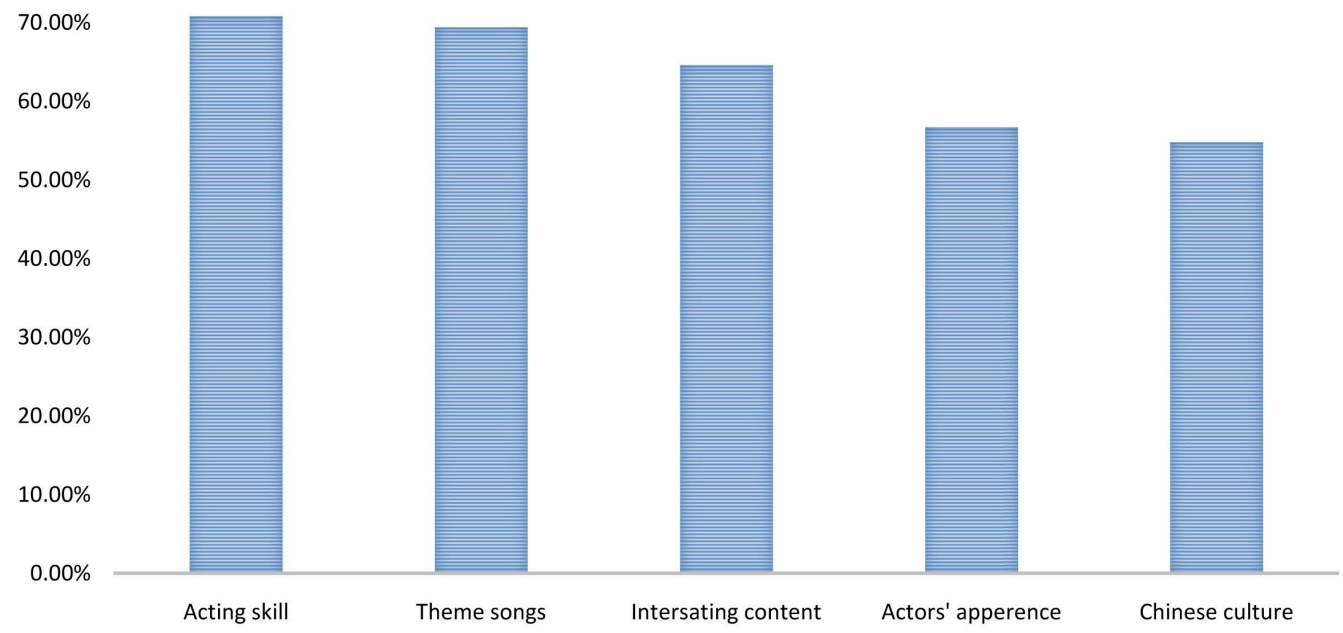

Figure 4. Communication effect analysis. 
According to the analysis of the survey results, the two TV series have high recognition in Thailand. The TV series Bao Zheng broadcast in the 1990s mainly focuses on the content of the story, the conveyed value, the reflection of social reality, and the acting skills of the actors to attract audiences, The TV series The Untamed broadcast in 2019 mainly attracts audiences from actors' acting skills, theme songs, story content, actors' appearance and Chinese culture. This survey result reflects the different ways in which different types of TV attract audiences. Chinese TV series can learn from the advantages of these two TV series in the future, choose the essence of them, and create works of art that people love to see.

To sum up, the author conducted a questionnaire survey on these two TV series from the four aspects of communication audience, communication content, communication channel and communication effect. The survey found that the awareness of these two TV series in Thailand is generally high. The contact channels for Chinese TV dramas are mainly social media and mass media. Through investigating the reasons why the Thai people are interested in Chinese TV dramas, it is found that most people like the content of Chinese TV dramas and Chinese actors, and more than half of them expressed their interest in Chinese culture and Chinese, too. According to the survey, Chinese TV dramas have a certain influence in Thailand in terms of the internet propaganda and the content of TV dramas themselves.

\section{Reasons for the Successful Dissemination of Chinese TV Series Bao Zheng and The Untamed in Thailand}

After the reform and opening up, China has gradually gone from being rich to becoming stronger, and Chinese culture has also been exported continuously with the development of the economy. In the 21 st century, the rapid development of the internet industry has broadened the channels for China's cultural output, and provides more possibilities for cultural prosperity. The spread of Chinese TV dramas in Thailand is an important manifestation of Chinese culture going global, and its existing success factors can provide reference for other cultures for going global.

\subsection{Analysis of Factors Contributing to the Successful Spread of Bao Zheng in Thailand}

The TV series (directed by 11 people including Liang Kaicheng, Sun Shupei, Hou Bowei, Chen Junliang, etc.) Bao Zheng is a feature-length TV series adapted and produced by Taiwan's China Television Company in 1993 based on the classic Three Heroes and Five Gallants, based on Three Heroes and Five Gallants, Bao Zheng is a prototype adapted from folklore. It mainly tells the story of Bao Zheng, who was honest and clean, judged the case for justice and redressed justice for the people.

\subsubsection{Narrative Content}

The plot of Bao Zheng is very vivid. The main characters of this TV series are 
Bao Zheng, Gongsun Ce, and Zhan Zhao. The three people have bright personalities. Bao Zheng dare to appeal for injustice for the people. Gongsun Ce is kind, meticulous, humble. Zhan Zhao is enthusiastic, righteous, and quite gentleman, and he has high martial arts and chivalrous and loyal characteristics. Different characters make this TV series highly watchable; secondly, the scenes of this TV series are very real, and the content is well-made. During the period when special effects and post production are still underdeveloped, the TV series are mainly filmed with real backgrounds. It basically reflects the life scene in ancient China and shows the folk customs of the Song Dynasty. At the same time, the TV series Bao Zheng is very long and influential, and the plot of the detective theme is very interesting. The story content is ups and downs, and the plot is complicated and confusing, leaving people with suspense, and contains a lot of details describing the detectives solving the case. The reasoning is rigorous. This is exactly the aesthetic characteristics and discourse advantage of this TV series.

The theme songs of Chinese TV dramas in the last century were very particular, and the lines were carefully considered. Therefore, the theme songs written were very classic and widely sung. The success of the theme songs also contributed to the promotion of the TV series Bao Zheng in Thailand and laid a positive and positive role.

\subsubsection{Spiritual Fit}

The TV series Bao Zheng was broadcast in the 1990s. During this period, the Thai bureaucracy prevailed and corruption was serious. The people wanted to have officials like Bao Zheng who were upright and honest and dared to be the masters of the people. Bao Zheng borrowed the past to satirize the present, pointed out the current malpractice, adopted critical realism, and expressed the rejection of corrupt officials and the expectation of upright officials. "Bao Zheng assuaged this antagonism by branding the few officials clean" [5]. It is against this historical background that the TV series Bao Zheng was spread.

The cultural compatibility between China and Thailand is very fit. At the same time, Thailand is also a developing country. The development of Thai society will also encounter similar problems with China. There are also similarities in cultural customs between China and Thailand. This TV series spread with correct values and positive energy that the Thai people can find a lot of common ground in society from this TV series, which will resonate with the whole society. Finally, this TV series has a very vivid description of human nature. Its purpose is to call for the beautiful and nature humanity, and lash the bad phenomena of social bureaucratic corruption. This content is in line with the good wishes of the Thai people.

\subsubsection{Cultural Basis}

Since ancient times, the communication between China and Thailand can be traced back thousands of years. Since the rise of tribute activities in the Ming Dynasty, the communication between China and Thailand have become closer. 
After the first Opium War, both China and Thailand were persecuted by western capitalist countries. At a time, a large number of people from the southeast coast of China went to Thailand by boat from Fujian, Guangdong and other regions, leading to a large number of Chinese and overseas Chinese settled in Thailand. The mixed living of Thais and Chinese is conducive to the spread of TV dramas. The TV drama Bao Zheng has a wide range of at the same time, the spread among the people has greatly enhanced the influence and social popularity of Bao Zheng.

\subsubsection{Social Policies}

The 1990s was a period of rapid economic growth in Thailand. In 1992, Thailand began to implement the seventh National Economic and Social Development Plan (1992-1996), emphasizing balance between economic and social development, maintaining the level of economic growth, and developing financial and capital markets. "In 1992, Thailand abolished the censorship system of TV, and TV policy is open and transparent" [6]. Despite the slow recovery, it is a driver to the Thai economy, growing at an annual rate of 8.1 percent, and reach to 8.8 percent in 1994. Economic growth has promoted the development of the entertainment industry and the spread of TV dramas.

Thailand's television policy was reformed in the 1990s. In 1992, the abolition of censorship and gradual relaxation of TV broadcasting conditions led to a booming media industry, which allowed a large number of imported dramas to be shown on Thai television. The Chinese TV series Bao Zheng was broadcast on thrid stations of Thailand, which is the second largest TV station in Thailand. It mainly broadcasts imported TV series. Moreover, Bao Zheng was broadcast during prime time and achieved great success in ratings. As people's living standards improve gradually in the 90s, public television ownership increases, which greatly promoted the spread of television drama in society. The third station also strengthened the TV group's cooperation with other countries, at the same time also introduced a lot of TVB drama, for the Chinese TV series won a good reputation in Thailand.

\subsection{Analysis of the Factors That Contributed to the Success of The Untamed in Thailand}

The Untamed (directed by Zheng Weiwen and Chen Jialin) is adapted from the Moxiang tongchou's novel named The Untamed. It is based on the background of five major families and tells the story of the two protagonists joining hands to explore the truth of previous years and protect the people and peace.

\subsubsection{Well-Made Production Is Essential}

The content of TV series and the production of costumes, makeup effect and props are the fundamental factors that determine the communication effect of TV series. With the popularity of Chinese costume dramas in Thailand in recent years, such as Nirvana in Fire, The Journey of Flower and Ten Miles of Peach Blossom, the overseas dissemination of Chinese costume dramas has gradually 
established a strong fan base. Meanwhile, it has also spread Chinese history and culture abroad and improved China's image as a great country.

The Untamed is adapted from MoXiang tong Chou's novel named The Untamed, and is jointly produced by Tencent Film and Xinpai Media. The ancient Chinese martial arts and the exquisite Han Chinese costume are deeply attracted to Thai audiences. The pictures of this TV series are well-made, and the costumes, makeup and props perfectly restore the dynasty background shown in the TV series. Before the TV series started filming, the actors of this crew studied traditional etiquette. There are five major families involved in the TV series, and each family has different martial arts moves and costumes. The TV series has restored the differences of different families from all aspects of detail. While appreciating the plot, it also gives the audience a beautiful visual enjoyment [7].

\subsubsection{Diversification of Communication Platforms}

A wide range of broadcasting platforms can greatly enhance the popularity of TV series in the region. In June 2019, The Untamed was uploaded on WeTV. Thai viewers can watch this TV series for free on this platform. This channel is also one of the most important channel to promote the spread of The Untamed in Thailand

In addition to WeTV, the The Untamed production team also uploaded the TV series on the two internet platforms in terms of Youtube and Netflix. At the same time, the TV series was broadcast on the third TV stations of Thailand. Multi-platform broadcasting meets the various needs of different users and also adapts to the viewing habits of each user.

\subsubsection{Active Propaganda}

The propaganda of TV series is an important factor influencing the dissemination of TV series. WeTV has opened an official Thai TV drama account on Twitter, where it publishes information related to TV drama broadcasts and extras around the actors on social media. The account currently has 200,000 followers and has published content related to The Untamed has more than thousands of people invovled, and will post related topics on the official account platform to allow fans to participate in the interaction. At the same time, it increase the popularity of TV series on the Thai online platform, such as letting fans vote for their favorite TV series endings, and release related sweepstakes, etc. [8]. Recently, the account released "Vote" to "Choose your favorite WeTV TV series" event, has received more than 1000 replies so far. On the Facebook platform, fans of The Untamed created a TV series-related group. Any member of the group can post content related to the TV series in the group and discuss with other fans, further increasing the popularity of the show on the internet.

In the offline aspect, the producer of The Untamed also organized various peripheral activities, such as holding fan meetings and main creative concerts, selling posters and gift boxes around TV dramas, publishing The Untamed national style music album, and at the same time the lipstick jointly launched by 
The Untamed and the Forbidden City, as well as other co-branded products, such as snacks, necklaces, beauty products, etc., are also sold. Propaganda through peripheral products not only increases the popularity of TV dramas, but also promotes China's cultural products to "go global".

\subsubsection{Benefit Effect of Topic Drainage}

Using the internet to create topics can expand the influence of TV dramas. In the current entertainment market, the fan economy and the culture of the fan circle are the primary concerns and content of various producers and brokerage companies. Excellent producers will create multiple hot topics for the work outside the play, and produce relevant content to guide Fans, in order to encourage fans to make peripheral creations around related topics. The two protagonists in The Untamed have a big contrast between the two personalities. The film crew used their emotional stories and personal personalities as perspectives and released related short videos to attract fans. Thai fans love and respect such dual male lead dramas very much. The film studio captured this market feature and made The Untamed a hit in Thailand.

The character setting of the characters in the play is also one of the reasons for the success of this TV series. Many other types of Chinese TV series have also achieved great success in Thailand, such as Zhen Huan and Nirvana in Fire. The love of TV series and characters only stays in the content of the TV series itself, and the degree of love for it does not extend beyond the drama. The reason is that the content of the struggles in these TV series is too far away from our lives, and it is not what people can do in daily life. Although The Untamed is also a TV series with the theme of ancient costumes, the producer has posted a lot of filming tidbits on its Twitter WeTV account, and has also released a lot of videos about the lives of the actors, shaping a lot of sunshine, uplifting and humorous teenagers with innocent hearts to give the audience a beautiful enjoyment, and uses a positive image to attract more fans who have a beautiful pursuit of passion and youth [9].

The mainstream values of striving hard and maintaining justice reflected in this TV series show the young generation's spirit of not being afraid of the world's hardships and not forgetting their original aspirations, and spreading the correct mainstream values in a way that young people can accept. It also raised the ideological realm of young people, spread traditional Chinese culture, and enhanced the influence of Chinese culture in Southeast Asia and even Japan and South Korea.

\section{Countermeasures}

As the main contemporary cultural and artistic form, TV dramas naturally carry the mission of improving people's spirit, cultural taste, and aesthetic ability [10]. Culture can establish connections between people in different countries, and Chinese TV dramas are constantly enriching their diversity to meet the needs of more different audiences. The media and communication methods used in dif- 
ferent eras are also different. The author selects two TV series Bao Zheng and The Untamed which are popular in different eras, and analyzes the reasons for their success. The author used a questionnaire survey to interview Thai people about the reasons that why they like or dislike these two TV dramas. Based on the analysis of the questionnaire survey, the following five cultural communication strategies should be drawn: 1) seek cultural exchange channels; 2) create high-quality content; 3) expand communication channels; 4) increase policy support; 5) improve translation level.

\subsection{Cultural Exchange Channels Seeking}

The emotional fit is the common ground between Chinese and Thai cultures. China is an ancient civilization with a history of 5000 years. It has a profound cultural heritage and strong cultural productivity. There are many historical stories and materials could be made into a TV series. China and Thailand have similar cultures and are geographically close. These two countries have a lot in common in history and culture. The religions of the two peoples have similarities. At the same time, they are deeply influenced by Asian culture. The cultures and customs of the two countries are also relatively similar. Using this advantage can create high-quality works that conform to the cultural aesthetics of the two countries.

According to the Thai TV host, the TV series The Untamed has become a phenomenal hit in Thailand. The two creators of the TV series have also gained a lot of fans in Thailand. The production team carried out related promotional activities and held concerts in Thailand. In recent years, Thai TV series have spread widely in China. From 2015 to 2020, TV dramas such as Girl From Nowhere and Interpreting My Love with Your Heart have set off a wave of Thai dramas in China. For a time, the audience of Thai dramas continues to grow. Many Thai celebrities also have a strong appeal in China. "At the same time, the kinship element should be strengthened so that viewers will first choose or prefer TV dramas with the same or similar language, culture and history" [11]. We should use this period to strengthen cultural exchanges between China and Thailand, enhance the friendship between the two peoples. At the same time, promoting outstanding Chinese TV dramas to Thailand as the Thai drama enters China.

\subsection{Create High-Quality Content}

Sophisticated production is an essential element for the successful spread of culture. TV transmission of overseas involve localization problem, we should be selectively output series, in recent years, China's TV series Nirvana in Fire, The Journey of Flower and Ten Miles of Peach Blossom and Zhen Huan and so on, a series of high-quality costume dramas in Thailand are very hot and wide praise of the Thai people. This also reminds us that while exporting Chinese traditional culture, we must also select well-produced TV series that can truly reflect the 
country's conditions and have correct values oriented to society. Such TV series will be welcomed and loved by audiences not only in China, but also overseas widely acclaimed.

However, there have also been some superficial works that only stayed at visual glitz in order to show off the so-called oriental culture, and even derived the creative attitude and aesthetic standards of "taking ugliness as beauty". We must criticize these [12]. The TV series created cannot be superficial, and the one-sided emphasis on the cultural differences between the two countries may make the audience feel disgusted and fail to achieve the purpose and effect of cultural dissemination. Based on the traditional Chinese virtues and the positive energy thoughts of socialist core values contained in Xi Jinping Thought on Socialism with Chinese Characteristics for a New Era, for example, in 2020, the Chinese TV series Nothing But Thirty (directed by Zhang Xiaobo) will hit South Korea. Based on a female perspective, the play tells about the different lives experienced by three urban women of different professions at the age of 30, encouraging women not to be restricted by traditional age concepts and to boldly pursue their own lives. The theme of "feminism" runs through the show, which promotes the positive thinking of independence and struggle. This kind of TV series with the theme of life and city not only shows the positive outlook of contemporary Chinese youth, but also the spirit of other countries, thus achieving success of spread.

\subsection{Broaden Communication Channels}

Explore various communication channels. From Bao Zheng to The Untamed, the export of Chinese TV series has shifted from single TV series sales and broadcasting on TV stations to simultaneous broadcasting on TV stations and the tnternet platforms. With the increase of the internet penetration in Thailand, online viewing has become the audience's first choice. At present, not only traditional TV media have their own network platforms, but also many independent video websites, such as YouTube, WeTV, and LineTV have their own, too. Watching TV shows on the internet is more selective. Viewers can directly search for keywords such as the name of the show, the name of the actor, and the country of origin. After logging in to the account, they can also rate and comment on the TV show. You can send comment on the screen, discuss the plot with other audiences in real time, and share your own feelings. The development of the internet allows viewers to watch TV series more flexible in time and methods. As a TV series publicity platform, we must make good use of this approach in terms of optimizing the platform experience and providing viewers with better services.

The advent of the "the internet plus" era has brought about a great change in the form of dissemination of TV dramas. In addition to traditional TV dissemination, we can spread something more on the internet in more forms. In 2019, WeTV used Facebook, Twitter, Instagram and other social media to conduct full-platform publicity and topic interaction. This method strengthened com- 
munication with fans and adapted to the social media usage habits of different audiences. In this information age, the social medium platform let more non-TV viewers understand this content.

\subsection{Policy Support Development}

The state's policy support promotes the overseas dissemination of Chinese TV dramas. On September 4, 2017, the State Administration of Radio, Film and Television, together with the Development and Reform Commission and the Ministry of Finance, jointly issued the Notice on Several Policies to Support the Prosperity and Development of TV Dramas to strengthen support for TV drama scripts and investment in TV dramas, improve the export incentive mechanism for TV dramas, and increase support for export of TV dramas. This notice is of great significance to the overseas dissemination of Chinese TV dramas. The export of Chinese film and television dramas can refer to South Korea's TV export support policies. The Korean government has provided top-level design, law formulation, national budget expenditures, administrative management, re-production of programs, and talent training to South Korea's cultural industry, especially TV dramas industry in the international management [13]. The Korean government integrated multiple departments, established the Korean Culture Promotion Research Institute and relevant departments to collect the Chinese market and Chinese pop culture trends to conduct research. The Korean government increased its capital investment, held international cultural exchange exhibitions, and formulated relevant laws guide the development of cultural industries.

The Chinese government should learn from South Korea's support policies, increasing support for TV dramas "going global", setting up a special department responsible for the export of overseas TV dramas, accurately grasping the audience and aesthetic characteristics of the exporting country, and improving while exporting film and television works. "Make full use of various resources, innovate the forms and means of cultural 'going out', absorb and draw lessons from the excellent cultural achievements of other countries in the world, enhance the influence and competitiveness of China's cultural products, and actively promote Chinese culture to face and go to the world" [14]. China's national image promotes the development of other related cultural industries.

\subsection{Improvement of Translation Level}

Language is the foundation of cultural communication. "Currently, domestic TV dramas that are popular overseas mainly rely on UGC, or subtitle group, to spontaneously produce subtitle in various languages, and very few rely on OGC, or internal translators of national organizations and film and television companies to carry out professional translation" [15]. If TV dramas are disseminated overseas without supplemented by excellent content translation, audiences will not be able to accurately understand the content expressed in TV dramas, and thus will not be able to achieve the output of Chinese culture and values. 
The Romance of the Three Kingdoms, one of the four classic Chinese classics, was translated by the then Minister of Finance and great poet Chao Phya Phra Klang by the Bangkok dynasty I. The more receptive translation makes the book The Romance of the Three Kingdoms widely spread in Thailand. The Thai translation used in the TV series on WeTV is the result of the joint translation of multiple subtitle groups. The translation quality is uneven, and even translation errors occur. For example, in the variety show Chuang, the translator translated "calm down" into "self peace", which made many Thai people misunderstood, and during this time period, many Thai audiences sent comments to express their incomprehension.

"The international dissemination of Chinese TV dramas might as well spend more manpower, material and financial resources on the internet, and actively seek various forms of cooperation with mainstream foreign video websites" [10]. In the translation of TV dramas, the government should focus on training translators to improve the quality of translation. For more professional and difficult content, native Thai speakers should be selected for translation and review, so as to fundamentally ensure the quality of the translation and correctly disseminate TV dramas. The values expressed in China promote the dissemination of Chinese TV dramas and Chinese culture.

\section{Conclusions}

The output of culture is a gradual process. The popularity of Chinese TV dramas in Thailand is a testament to the compatibility of culture and values between China and Thailand. It also shows the importance of network communication methods for TV drama dissemination under the modern internet economy. There are still many problems in the overseas dissemination of TV dramas in our country. We should continuously improve the production level and publicity ability of TV dramas in our country, create well-produced film and television works that promote correct values, and use new media platforms to expand the scope of publicity and increase the breadth and intensity of publicity. In the process of continuous dissemination of TV dramas, we must strengthen international exchanges and cooperation, take into account the strength of the government and the private sector, and play a positive role in promoting Chinese culture going global.

This questionnaire still has its own limitations. The first is that this questionnaire is mainly distributed through the internet, and most of the interviewees are young people. The results of this questionnaire may reflect more young people's views on the two TV series, and more older groups have not yet been involved; the second is the survey is mainly distributed on topics related to Chinese TV dramas on Thai social media platforms. Cross-border questionnaires are difficult to collect. The total amount of data that can be analyzed is comprehensive and cannot reflect the surveyed issues from an overall perspective. In the future, other scholars can further study and improve this research in the above two aspects. 


\section{Conflicts of Interest}

The authors declare no conflicts of interest.

\section{References}

[1] Huang, H.K. (2006) The Spread of Ancient Chinese Novels in Thailand. Social Science Front, No. 4, 112-119.

[2] Dong, Z.D. (2019) Analysis of the Popularity of Taiwanese Drama Bao Zheng in Thailand. Borealis, No. 7, 80-82.

[3] Lasswell, H. (2003) The Structure and Function of Communication in Society. Translated by Xie Jinwen, Fudan University Press, Shanghai.

[4] http://www.199it.com/archives/563961.html

[5] Yang, X.L. (2019) Exploration of the Humanistic Psychological Structure of Bao Zheng TV Series from the Perspective of Clean Government Culture. Aesthetics (Part 2), No. 1, 41-46.

[6] Li, F.B. (2016) On the Dissemination of Chinese TV Series in Thailand. Modern Audio-Video Arts, No. 5, 33-37.

[7] Wu, L. (2019) Research the Successful Factors of Cultural Output from the Popularity of The Untamed Overseas. Journal of Tasting the Classics, No. 6, 29-32.

[8] Li, Y. and Shao, L. (2020) A Study on the Overseas Integration and Dissemination of Network Novel Adaptation from The Untamed. West China Broadcasting TV, No. 1, 74-75.

[9] Yang, Y. and Du, C.F. (2020) An Analysis of the External Communication of Chinese Costume Dramas Based on the "Frame" Theory-A Case Study of Legend of Zhen Huan and The Untamed. Today's Massmedia, 28, 118-120.

[10] Zhang, Y.H. (2003) Chinese TV Dramas and Contemporary Popular Culture Thoughts-A Discussion with Professors Zeng Qingrui and Yin Hong. Modern Communication, No. 1, 42-45.

[11] Xie, X.L. (2019) The Spread of Yunnan-Themed Teleplays in Southeast Asia and the Cultural Identity of Overseas Chinese since the New Century. Yunnan Normal University, Kunming.

[12] Jia, J. (2020) Expansion of "Cultural Territory": Overseas Communication Strategy of Domestic TV Series. Contemporary TV, No. 9, 56-58+72.

[13] Zhang, Z.Y., Su, F. and Chang, F.X. (2014) The Korean Government's Support for the Internationalization of the Korean TV Drama Industry. Periodical of Ocean University of China (Social Sciences Edition), No. 5, 45-55.

[14] Qu, D.X. (2007) From the Perspective of Costume Dramas and Their Similar Types, the Development of TV Series Typing. China Television, No. 3, 33-37.

[15] Wu, W.C. (2018) Analysis of the Status Quo of Overseas Dissemination of Domestic TV Series. International Communications, No. 1, 35-37. 